\title{
Current Evidence on Using Platelet Rich Plasma as a Therapeutic Modality for Veterinary Orthopedic Conditions
}

\author{
H.M. Suranji Wijekoon* and D.D. Niranjala de Silva \\ Department of Veterinary Clinical Sciences, Faculty of Veterinary Medicine and Animal Science, University of Peradeniya, Peradeniya 20400, Sri Lanka \\ *Corresponding author's Email: suranjisk@ gmail.com; (iDORCiD: 0000-0002-7053-5268
}

\begin{abstract}
This review evaluates the findings of available clinical literature on the use of platelet-rich plasma (PRP) to develop evidence-based recommendations for treating various musculoskeletal issues that arise in veterinary practice. The use of PRP-based treatments for various orthopedic conditions is rapidly evolving as a promising treatment modality; however, its true effectiveness has yet to be elucidated. Application of PRP has been reported in humans for a variety of orthopedic conditions. Although the majority of the veterinary literature on PRP reports its use in equine patients, there is a dearth of evidence addressing its use in canine patients. Nevertheless, evidence of the efficacy of PRP has appeared to be highly variable depending on its specific indication, particularly in musculoskeletal disorders. This review aims to present the available information on the efficacy of PRP therapy in veterinary orthopedic conditions and describes factors influencing its use, the limitations of PRP therapy, and future directions of PRP research and therapy.
\end{abstract}

Keywords: Musculoskeletal diseases, Orthopedic, Platelet-rich plasma, Veterinary

\section{INTRODUCTION}

Autologous platelet-rich plasma (PRP) is a biological preparation made from the patient's own plasma that contains a platelet concentration exceeding the baseline values of the whole blood. The use of a patient's own biological materials, such as PRP or plasma rich in growth factors, for tissue healing is a welcoming and alternative therapeutic approach with fewer side effects and lower cost, in comparison with other techniques. Induction of hemostasis, production of antiinflammatory cytokines, and release of growth factors at the injured sites are the factors influencing the use of bloodderived compounds intensively in the clinical field (Alsousou et al., 2009; Fortier et al., 2011). Owing to the release of cytokines and other growth factors after degranulation, platelets play a key role in the inflammation and healing process (Garbin and Olver, 2020). The PRP secretes several growth factors (Figure 1) at the injured site and promotes mitogenesis as well as angiogenesis in the tissue (Eppley et al., 2006; Filardo et al., 2013; Hsu et al., 2013). These growth factors include platelet-derived growth factor, transforming growth factor- $\beta 1$, transforming growth factor- $\beta 2$, vascular endothelial growth factor, basic fibroblastic growth factor, and epidermal growth factor. In addition to these factors, PRP contains adhesion molecules that promote bone formation. These molecules include fibrin, fibronectin, and vitronectin (Marx, 2001).

Given its regenerative properties, PRP has been applied in a wide range of clinical applications, including musculoskeletal injuries. A considerable number of recent studies have shown PRP to be efficacious in managing many different orthopedic conditions and soft tissue injuries by going beyond its limited uses in dentistry and maxillofacial surgical interventions (Dragoo et al., 2012; Abrams et al., 2013; Filardo et al., 2013). Several studies have also documented the efficacy of PRP for the management of osteoarthritis (Kon et al., 2011; Filardo et al., 2012; Franklin and Cook, 2013; Khoshbin et al., 2013) as well as soft tissue healing (Dragoo et al., 2012; Dragoo et al., 2014). Platelets recruit, stimulate, and provide a scaffold for stem cells, hence the synergistic effect of PRP with stem cell therapy also has been documented in cartilage, bone, and soft tissue healing (Del et al., 2008; Dohan et al., 2008; Drengk et al., 2009; Mishra et al., 2009; Xie et al., 2012; Broeckx et al., 2014). In vitro studies demonstrated that PRP can promote the synthesis of proteoglycan and type II collagen, which are important for the structural organization of cartilage framework while down regulating inflammatory mediators, such as interleukin-1 (IL-1) (Smyth et al., 2013; Zhu et al., 2013; Kazemi and Fakhrjou, 2015). Apart from cartilage repair, PRP promotes repair of damaged tendons which tend to heal slowly after injury (Anitua et al., 2007). Despite these promising results, some studies have disclosed that the addition of larger concentrations of PRP induces a higher rate of apoptosis assuming that a higher concentration of growth factors to the cell may have a detrimental rather than a beneficial effect (Dhillon et al., 2015).

Musculoskeletal disorders are the most common consequences of physical overstrain or trauma in athletic humans as well as animals, which has a negative effect on physical performance and ultimately the quality of life. Regenerative therapy for racehorses is a rapidly growing field of research due to its potential substantial economic impact on the horse 
industry. In fact, the speed of healing is a crucial factor in degenerative joint diseases and is a priority in veterinary research both for the quality of life of horses and a rapid return to competition. Evaluation of new treatments for musculoskeletal injuries in horses could benefit both equine and human medicine hence racehorses can serve as a valuable large animal model for evaluation of new human therapeutics (Frisbie et al., 2006).

This review aims to present the available information on the efficacy of PRP therapy in veterinary orthopedic conditions as well as factors influencing its use, the limitations of PRP therapy, and future directions of PRP research and therapy.

\section{Knee osteoarthritis}

Osteoarthritis is the most common form of arthritis in humans and animals. Osteoarthritis affects the entire joint, including the cartilage, tendons, synovial fluid, synovial membrane, and bone. Several animal studies on osteoarthritis characterized the degeneration of the cartilage and soft tissues, hypertrophy of bone at the margins, as well as changes in the synovial membrane and fluid viscosity (Vaughn-Scott and Taylor, 1997; Pasquini et al., 2007; Wijekoon et al., 2019). As the cartilage continues to wear off and deteriorate completely, it causes friction between the bones, which leads to inflammation, thickening of soft tissues, and loss of mobility of the joint (Pasquini et al., 2007). The treatment of knee osteoarthritis adopts both surgical and non-surgical options; however, nonsurgical treatments have recently captured greater attention. Most of the current treatment modalities for osteoarthritis focus on treating the symptoms, leading to an increase in disease-modifying treatments, such as PRP. The PRP is an efficient treatment option for osteoarthritis in numerous species due to its potential anabolic and anti-catabolic effects and the ease of preparation (Mifune et al., 2013; Carmona et al., 2016; Moussa et al., 2017). Amongst the several different options, such as nonsteroidal anti-inflammatory drugs (NSAIDs), corticosteroids, and disease-modifying osteoarthritis drugs (DMOADs) (Wijekoon et al., 2019) which are used to relieve pain while regenerating the tissue, the use of PRP has emerged as a novel treatment method. Serial intra-articular PRP injections could decrease the pain while increasing articular function. The studies conducted on horses have demonstrated that injection of autologous adipose tissue mixed with PRP can be safely performed and is well-tolerated (Benbo et al., 2016). Previous studies on the use of PRP in racing horses for the treatment of degenerative joint disease have shown promising clinical outcomes due to increased mesenchymal stem cells proliferation (Figure 2), enhanced chondrogenic differentiation, and improved cartilage regeneration (Mishra et al., 2009; Rubio-Azpeitia and Andia, 2014; Atashi et al., 2015). It has been reported that an autologous protein solution and a platelet-derived product could reduce pain and lameness, compared to saline in client-owned dogs and human patients with osteoarthritis after one year of treatment (Kon et al., 2018). In a meniscal-tear rat model, the platelet-derived product did not demonstrate clinical improvement, but it did reduce cartilage degeneration (King et al., 2017).

\section{Treatment of tendon and ligament injuries}

Tendon and ligament injuries affect animal performance and end the career of a horse or dog hence, it is regarded as a career-limiting disease. Proper early treatment is vital to restore function and structure. The composition of numerous cytokines and growth factors in PRP is predicted to improve clinical outcomes by enhancing tenocyte proliferation (Mazzocca et al., 2012b), collagen and matrix synthesis (Smith et al., 2006; Schnabel et al., 2007), and through influencing vascular density (Bosch et al., 2011). In vitro and in vivo models have confirmed the antiinflammatory effects of PRP on tendon inflammation by suppressing the levels of components of the prostaglandin biosynthetic pathway (Zhang et al., 2013).

\section{Muscles injuries}

Similar to tendon healing, the use of PRP has shown clinical efficacy in the treatment of muscle injuries through cell proliferation, differentiation, and tissue remodeling after the initial inflammatory response. Previous clinical studies on human patients with muscle injuries have shown a faster recovery and rapid return to play when PRP treatment was carried out simultaneously with rehabilitation in comparison to the rehabilitation alone (Hamid et al., 2014; Reurink et al., 2014).

\section{Fracture and nonunion Management}

Among the several strategies for the treatment of bone defects, the most recommended method for filling the small bone defects is to apply bone substitutes or conventional cancellous autologous bone grafting (Hinsche et al., 2003; Calori et al., 2011; Guerado and Fuerstenberg, 2011; Zimmermann and Moghaddam, 2011). Appropriate aligning of the fracture site using internal or external fixators is the main strategy for the management of nonunion fractures. However, novel strategies, such as electromagnetic fields, biodegradable implants, recombinant bone morphogenetic protein 7, and PRP treatment (Akmaz et al., 2004; Calori et al., 2006; Griffin et al., 2011) have been introduced with different outcomes. A meta-analysis found that there is a scarcity of standard randomized clinical trials to investigate the effectiveness of PRP application on the healing rate of nonunion of long bones (Griffin et al., 2012). Several animal 
experiments have demonstrated that treatment with PRP in combination with autologous cancellous bone grafting leads to a significant improvement in bone regeneration, in comparison with the isolated application of autologous cancellous bone in long bones of mini-pigs during 6 weeks (Griffin et al., 2011). Considering the above findings, PRP treatment may be promising in overcoming the surgical challenges of the correction of nonunion fractures and improving the current fracture treatments and management by conducting appropriate clinical trials.

\section{Factors affecting the effectiveness of PRP}

Although PRP is a promising treatment modality with clear evidence of safety in musculoskeletal medicine, efficacy has been highly dependent on composition and indication. The cellular and molecular content of PRP also depends on the procedure used for preparation (Carmona et al., 2013). The PRP is usually used as an autologous treatment, and product standardization is difficult due to different characteristics and variations among individuals. In horses, inherent factors such as age, breed, and gender affect the whole blood cellular composition, which could potentially influence the effects of PRP (Giraldo et al., 2013), hence clinicians should consider the inherent features of the animal when using platelet-derived products.

The response to PRP as a treatment is affected by PRP composition as well as the condition and type of tissue treated. In many studies on different tissues, lower concentrations of platelets had an insufficient/suboptimal clinical effect, and higher concentrations had inhibitory effects on promoting angiogenesis in cell cultures (Giusti et al., 2009) while leading to apoptosis, downregulation, and desensitization of growth factor receptor, indicating a paradoxical effect on the healing process (Gruber et al., 2002; Haynesworth et al., 2002). Therefore, the selection of intermediate concentrations of platelets might be appropriate for clinical use.

The method used in PRP activation is another factor that should be considered which could have a variable impact on the outcome in this therapy. Platelets can be activated through physical or chemical methods. The different methods of activation are critical factors that should be considered in growth factor concentration (Mazzocca et al., 2012b). Activation of PRP in humans is usually done using thrombin, $\mathrm{CaCl}_{2}$ (Textor and Tablin, 2012), or with a combination of both (Bendinelli et al., 2010). Some studies suggested the use of $\mathrm{CaCl}_{2}$ for PRP activation as an effective and inexpensive method that releases more than $80 \%$ growth factors (Textor and Tablin, 2012). Other important factors that determine the effectiveness of the PRP treatment are the condition of the tissue before the use of platelet products (acute versus chronic inflammation) as well as the age of the recipient. Better outcomes were reported in younger subjects, in comparison with older patients, and more mild osteoarthritis cases, compared to severe ones (Textor and Tablin, 2012).

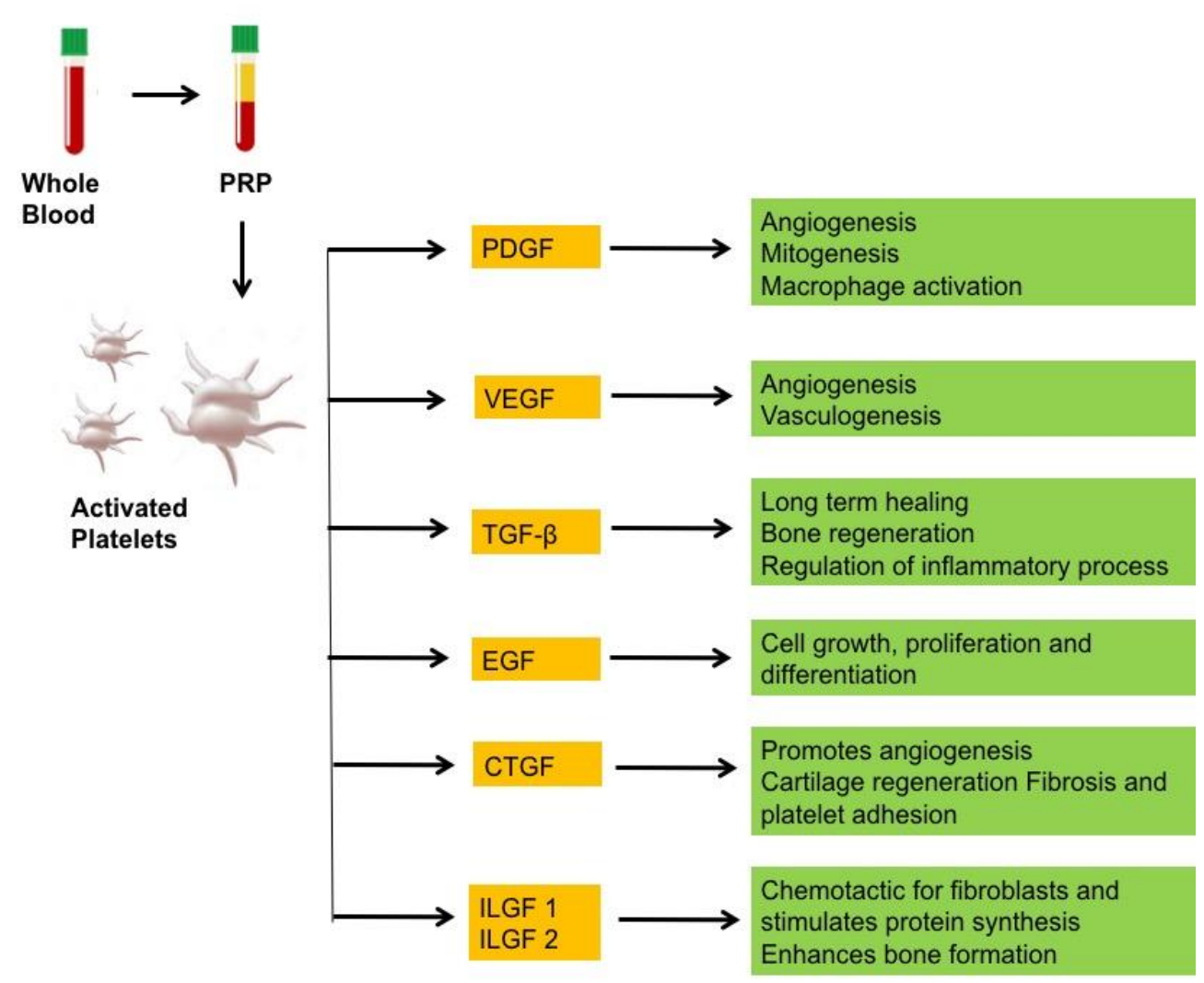

Figure 1. Mechanism of action of PRP. Various growth factors are produced by activated platelets at the site of tissue injury and accelerate the healing and tissue regeneration. PRP: Platelet-rich plasma, PDGF: Platelet derived growth factor, VEGF: Vascular endothelial growth factor, TGF- $\beta$ : Transforming growth factor beta, EGF: Epidermal growth factor, CTGF: Connective tissue growth factor, ILGF: Insulin like growth factor 


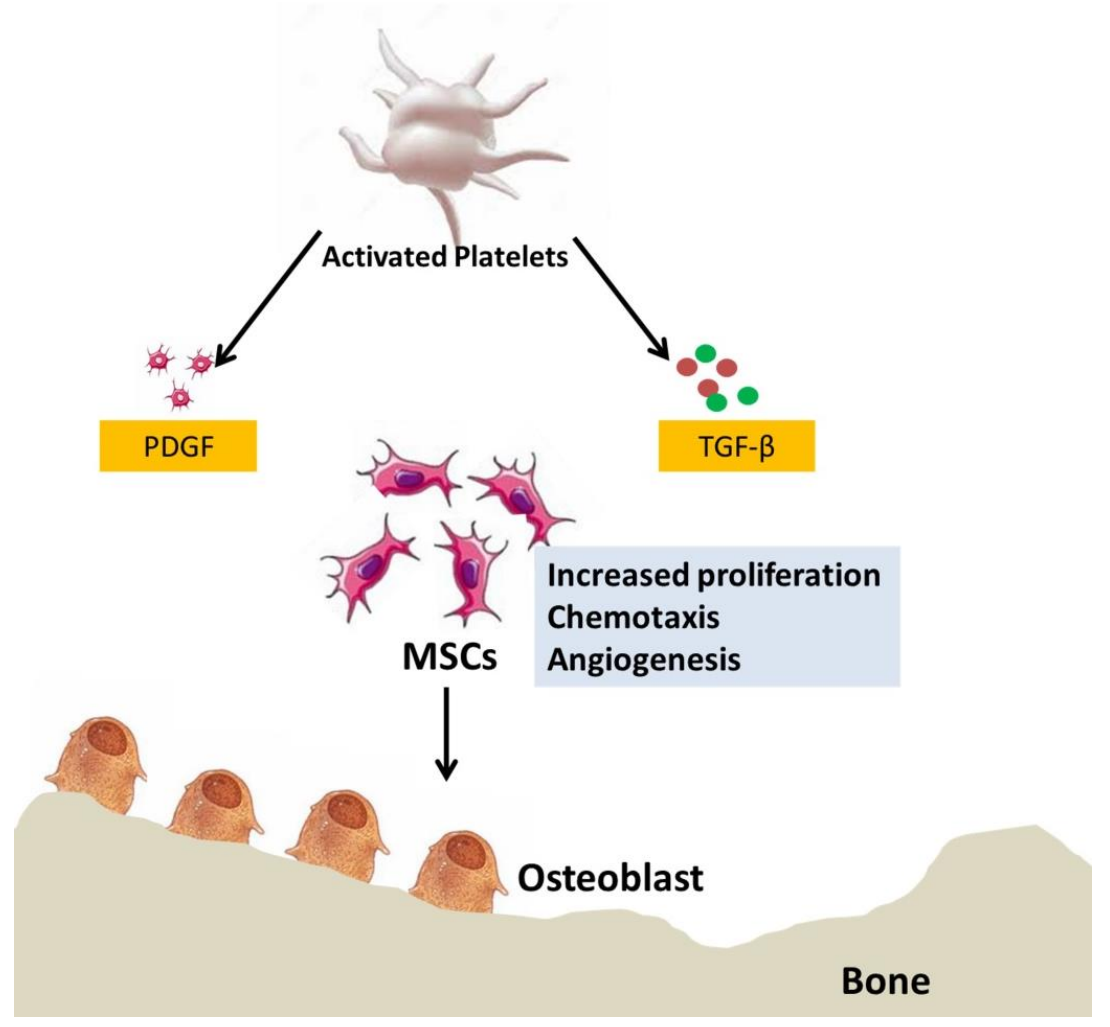

Figure 2. Role of PRP on stem cells in bone and cartilage formation. PRP: Platelet-rich plasma, PDGF: Platelet derived growth factor, TGF- $\beta$ : Transforming growth factor beta, MSCs: Mesenchymal stem cells

\section{CONCLUSION}

It is justifiable for veterinary practitioners to embark on using PRP therapy as a novel modality of treatment for a variety of orthopedic conditions. In response to a growing interest among both patients and surgeons in the use of PRP, recent studies have reported positive outcomes in a variety of conditions. However, due to the paucity of guidelines developed by professional organizations, several important aspects need to be addressed with critical review and rigorous clinical studies. Such efforts would encourage practitioners to formulate a cost-effective, efficacious algorithm for the use of PRP in animals with orthopedic conditions.

\section{DECLARATIONS}

\section{Authors' contributions}

Both authors participated equally in study design, data collection, and writing. The authors approved the final draft of the manuscript.

\section{Competing interests}

The authors declare no conflict of interests.

\section{REFERENCES}

Abrams GD, Frank RM, Fortier LA, and Cole BJ (2013). Platelet-rich plasma for articular cartilage repair. Sports Medicine and Arthroscopy Review, 21: $213-219$.
https://journals.lww.com/sportsmedarthro/Abstract/2013/12000/Platelet_rich_Plasma_for_Articular_Cartilage.7.aspx

Akmaz I, Kiral A, Pehlivan O, Mahirogullari M, Solakoglu C, and Rodop O (2004). Biodegradable implants in the treatment of scaphoid nonunions. International Orthopedic, 28(5): 261-266. Available at: https://link.springer.com/article/10.1007\%2Fs00264-004-0580-Z

Alsousou J, Thompson M, Hulley P, Noble A, and Willett K (2009). The biology of platelet-rich plasma and its application in trauma and orthopedic surgery: a review of the literature. The Journal of Bone Joint Surgery (Br), 91: 987-996. DOI: https://doi.org/10.1302/0301-620X.91B8.22546

Anitua E, Sánchez M, Orive G, and Andía I (2007). The potential impact of the preparation rich in growth factors (PRGF) in different medical fields. Biomaterials, 28(31): 4551-4560. DOI: https://www.doi.org/10.1016/j.biomaterials.2007.06.037

Atashi F, Jaconi ME, Pittet-Cuénod B, and Modarressi A (2015). Autologous platelet-rich plasma: a biological supplement to enhance adipose-derived mesenchymal stem cell expansion. Tissue Engineering Part C Methods, 21(3): 253-262. DOI: https://doi.org/10.1089/ten.tec.2014.0206

Benbo F, Eraud J, Philandrianos C, Bertrand B, Silvestre A, Veran J, Sabatier F, Magalon G, and Magalon J (2016). Combined use of platelet rich plasma \& micro-fat in sport and race horses with degenerative joint disease: preliminary clinical study in eight horses. Muscles, Ligaments and Tendons Journal, 6(2): 198-204. Available at: http://www.mltj.online/wp-content/uploads/2019/01/Combined-use-of-platelet-rich-plasma-microfat-in-sport-and-race-horses-with-degenerative-joint-disease-preliminary-clinical-study-in-eight-horses.pdf 
Bendinelli P, Matteucci E, Dogliotti G, Corsi MM, Banfi G, and Maroni P (2010). Molecular basis of anti-inflammatory action of platelet-rich plasma on human chondrocytes: mechanisms of NF-kB inhibition via HGF. Journal of Cell Physiology, 225: 757-766. DOI: https://www.doi.org/10.1002/jcp.22274

Bosch G, Moleman M, Barneveld A, van Weeren PR, and van Schie HT (2011). The effect of platelet-rich plasma on the neovascularization of surgically created equine superficial digital flexor tendon lesions. Scandinavian Journal of Medicine and Science in Sports, 21(4): 554-561. DOI: https://www.doi.org/10.1111/j.1600-0838.2009.01070.x

Broeckx S, Zimmerman M, Crocetti S, Suls M, Marien T, and Ferguson SJ (2014). Regenerative therapies for equine degenerative joint disease: a preliminary study. PLoS One, 9(1): e85917. DOI: https://doi.org/10.1371/journal.pone.0085917.t003

Calori GM, D'Avino M, Tagliabue L, Albisetti W, d'Imporzano M, and Peretti G (2006). An ongoing research for evaluation of treatment with BMPs or AGFs in long bone non-union: protocol description and preliminary results. Injury, 37: 43-50. DOI: https://www.doi.org/10.1016/j.injury.2006.08.023

Calori GM, Mazza E, Colombo M, and Ripamonti C (2011). The use of bone-graft substitutes in large bone defects: any specific needs? Injury, 42: 5663. DOI: https://www.doi.org/10.1016/j.injury.2011.06.011

Carmona JU, López C, and Sandoval JA (2013). Review of the current available systems to obtain platelet related products to treat equine musculoskeletal injuries. Recent Patent on Regenerative Medicine, 3(2): 148-59. DOI: https://doi.org/10.2174/2210296511303020005

Carmona JU, Ríos DL, Lopez C, Alvares ME, Perez JE, and Bohorquez ME (2016). In vitro effects of platelet-rich gel supernatants on histology and chondrocyte apoptosis scores, hyaluronan release and gene expression of equine cartilage explants challenged with lipopolysaccharide. BMC Veterinary Research, 12: 135. DOI: https://doi.org/10.1186/s12917-016-0759-8

Del Bue M, Riccò S, Ramoni R, Conti V, Gnudi G, and Grolli S (2008). Equine adiposetissue derived mesenchymal stem cells and platelet concentrates: their association in vitro and in vivo. Veterinary Research Communication, 32: 51-55. DOI: https://doi.org/10.1007/s11259-008$\underline{9093-3}$

Dhillon MS, Karna SK, Dhatt SS, Behera P, and Bhatia A (2015). Can platelet rich plasma stimulate human ACL growth in culture? A preliminary experience. Muscles Ligaments Tendons Journal, 5(3): 156-161. DOI: https://doi.org/10.11138/mltj/2015.5.3.156

Dohan EDM, Rasmusson L, and Albrektsson T (2008). Classification of platelet concentrates: from pure platelet-rich plasma (P-PRP) to leukocyteand plateletrich fibrin (L-PRF). Trends Biotechnology, 27(3): 158-167. DOI: https://doi.org/10.1016/j.tibtech.2008.11.009

Dragoo JL, Braun HJ, Durham JL, Ridle BA, Odegaard JI, and Luong R (2012). Comparison of the acute inflammatory response of two commercial platelet rich plasma systems in healthy rabbit tendons. American Journal of Sports Medicine, 40(6): 1274-1281. DOI: https://doi.org/10.1177/0363546512442334

Dragoo JL, Wasterlain AS, Braun HJ, and Nead KT (2014). Platelet-rich plasma as a treatment for patellar tendinopathy: a double-blind, randomized controlled trial. Am J Sports Medicine, 42(3): 610-618. DOI: https://doi.org/10.1177/0363546513518416

Drengk A, Zapf A, Stürmer EK, Stürmer KM, and Frosch KH (2009). Influence of plateletrich plasma on chondrogenic differentiation and proliferation of chondrocytes and mesenchymal stem cells. Cells Tissues Organs, 189: 317-326. DOI: https://doi.org/10.1159/000151290

Eppley BL, Pietrzak WS, and Blanton M (2006). Platelet-rich plasma: a review of biology and applications in plastic surgery. Plastic and Reconstructive Surgery, 118(6): 147-159. DOI: https://doi.org/10.1097/01.prs.0000239606.92676.cf

Filardo G, Kon E, Di Martino A, Di Matteo B, Merli ML, and Cenacchi A (2012). Platelet-rich plasma vs hyaluronic acid to treat knee degenerative pathology: study design and preliminary results of a randomized controlled trial. BMC Musculoskeletal Disorders, 13: 229. DOI: http://www.biomedcentral.com/1471-2474/13/229

Filardo G, Kon E, Roffi A, Di Matteo B, Merli ML, and Marcacci M (2013). Platelet rich plasma: why intra-articular? A systematic review of preclinical studies and clinical evidence on PRP for joint degeneration. Knee Surgery Sports Traumatology Arthroscopy, 23(9): 2459-2474. DOI https://doi.org/10.1007/s00167-013-2743-

Fortier LA, Barker JU, Strauss EJ, McCarrel TM, and Cole BJ (2011). The role of growth factors in cartilage repair. Clinical Orthopedics and Related Research, 469: 2706-2715. DOI: https://doi.org/10.1007/s11999-011-1857-3

Franklin S, and Cook J (2013). Prospective trial of autologous conditioned plasma versus hyaluronan plus corticosteroid for elbow osteoarthritis in dogs. Canadian Veterinary Journal, 54: 881-884. Available at: https://www.ncbi.nlm.nih.gov/pmc/articles/PMC3743576/

Frisbie DD, Cross MW, and Mc Ilwraith CW (2006). A comparative study of articular cartilage thickness in the stifle of animal species used in human pre-clinical studies in comparison with articular cartilage thickness in the human knee. Veterinary and Comparative Orthopedic and Traumatology, 19: 142-146. DOI: https://doi.org/10.1055/S-0038-1632990

Garbin LC, and Olver CS (2020). Platelet-rich product and their application to osteoarthritis. Journal Equine Veterinary Science, 86: 102820 DOI: https://doi.org/10.1016/j.jevs.2019.102820

Giraldo CE, Lopez C, Alvarez ME, Samudio IJ, and Carmona JU (2013). Effects of the breed, sex and age on cellular content and growth factor release from equine pure- platelet rich plasma and pure-platelet rich gel. BMC Veterinary Research, 9: 29. DOI: https://doi.org/10.1186/1746-6148-9-29

Giusti I, Rughetti A, D’Ascenzo S, Millimaggi D, Pavan A, Dell-Orso L, and Dolo V (2009). Identification of an optimal concentration of platelet gel for promoting angiogenesis in human endothelial cells. Transfusion, 49: 771-778. DOI: https://doi.org/10.1111/j.1537-2995.2008.02033.x

Griffin XL, Costa ML, Parsons N, and Smith N (2011). Electromagnetic field stimulation for treating delayed union or non-union of long bone fractures in adults. Cochrane Database of Systematic Reviews, 4: CD008471. DOI: https://doi.org/10.1002/14651858.CD008471.pub2

Griffin XL, Wallace D, Parsons N, and Costa ML (2012). Platelet rich therapies for long bone healing in adults. Cochrane Database of Systematic Reviews, 7: CD009496. DOI: https://doi.org/10.1002/14651858.CD009496.pub2

Gruber R, Varga F, Fischer MB, and Watzek G (2002). Platelets stimulate proliferation of bone cells: involvement of platelet-derived growth factor, microparticles and membranes. Clinical Oral Implants Research, 13: 529-535. DOI: https://doi.org/10.1034/j.1600-0501.2002.130513.x

Guerado E, and Fuerstenberg CH (2011). What bone graft substitutes should we use in post-traumatic spinal fusion? Injury, 42: 64-71. DOI: https://doi.org/10.1016/j.injury.2011.06.200

Hamid MS A, Mohamed Ali MR, Yusof A, George J, and Lee LPC (2014). Platelet-rich plasma injections for the treatment of hamstring injuries: a randomized controlled trial. American Journal of Sports Medicine, 42: 2410-2418. DOI: https://doi.org/10.1177/0363546514541540

Haynesworth SE, Kadiyala KS, Liang LN, and Bruder SP (2002). Mitogenic stimulation of human mesenchymal stem cells by platelet release suggests a mechanism for enhancement of bone repair by platelet concentrates. Boston, USA: Proceedings of the 48th Meeting of Orthopedic Research Society, p. 462. Available at: http://www.ors.org/Transactions/48/0462.pdf

Hinsche AF, Giannoudis PV, Matthews SE, and Smith RM (2003). Spontaneous healing of large femoral cortical bone defects: does genetic predisposition play a role? Acta Orthopaedica Belgica, 69(5): 441-446. Available at: https://pubmed.ncbi.nlm.nih.gov/14648954/

Hsu WK, Mishra A, Rodeo SR, Fu F, Terry MA, and Randelli P (2013). Platelet rich plasma in orthopedic applications: evidence-based recommendations for treatment. Journal of American Academy of Orthopedic Surgeons, 21: 739-748. DOI: https://doi.org/10.5435/JAAOS-21$\underline{12-739}$

Kazemi D, and Fakhrjou A (2015). Leukocyte and platelet rich plasma (L-PRP) versus leukocyte and platelet rich fibrin (L-PRF) for articular cartilage 
repair of the knee: a comparative evaluation in an animal model. Iranian Red Crescent Medical Journal, 17(10): e19594. DOI: https://doi.org/10.5812/ircmj.19594

Khoshbin A, Leroux T, Wasserstein D, Marks P, Theodoropoulos J, and OgilvieHarris D (2013). The efficacy of platelet-rich plasma in the treatment of symptomatic knee osteoarthritis: a systematic review with quantitative synthesis. Arthroscopy, 29(12): 2037-2048. DOI: https://doi.org/10.1016/j.arthro.2013.09.006

King W, Bendele A, Marohl T, and Woodell-May J (2017). Human blood-based anti-inflammatory solution inhibits osteoarthritis progression in a meniscal-tear rat study. Journal of Orthopedic Research, 35: 2260-2268. DOI: https://doi.org/10.1002/jor.23528

Kon E, Engebretsen L, Verdonk P, Nehrer S, and Filardo G (2018). Clinical outcomes of knee osteoarthritis treated with an autologous protein solution injection: a 1-year pilot double-blinded randomized controlled trial. American Journal of Sports Medicine, 46: 171-180. DOI: https://doi.org/10.1177/0363546517732734

Kon E, Mandelbaum B, Buda R, Filardo G, Delcogliano M, and Timoncini A (2011). Platelet-rich plasma intra-articular injection versus hyaluronic acid visco supplementation as treatments for cartilage pathology: from early degeneration to osteoarthritis. Arthroscopy, 27(11): 1490-1501. DOI: https://doi.org/10.1016/j.arthro.2011.05.011

Marx RE (2001). Platelet-rich plasma (PRP): what is PRP and what is not PRP? Implant Dentistry, 10(4): 225-228. DOI: https://doi.org/10.1097/00008505-200110000-00002

Mazzocca AD, McCarthy MB, Chowaniec DM, Cote MP, Romeo AA, and Bradley JP (2012a). Platelet-rich plasma differs according to preparation method and human variability. Journal of Bone Joint Surgery American, 94: 308-316. DOI: https://doi.org/10.2106/JBJS.K.00430

Mazzocca AD, McCarthy MB, Chowaniec DM, Dugdale EM, Hansen D, and Cote MP (2012b). The positive effects of different platelet-rich plasma methods on human muscle, bone, and tendon cells. American Journal of Sports Medicine, 40(8): 1742-1749. DOI: https://doi.org/10.1177/0363546512452713

Mifune Y, Matsumoto T, Takayama K, Ota S, Meszaros LB, and Usas A (2013). The effect of platelet-rich plasma on the regenerative therapy of muscle derived stem cells for articular cartilage repair. Osteoarthritis Cartilage, 21: 175-185. DOI: https://doi.org/10.1016/j.joca.2012.09.018

Mishra A, Tummala P, King A, Lee B, and Kraus M (2009). Buffered platelet rich plasma enhances mesenchymal stem cells proliferation and chondrogenic differentiation. Tissue Engineering Part C Methods, 15: 431-435. DOI: https://doi.org/10.1089/ten.tec.2008.0534

Moussa M, Lajeunesse D, Hilal G, El Atat O, Haykal G, and Sehal R (2017). Platelet rich plasma (PRP) induces chondroprotection via increasing autophagy, anti- inflammatory markers, and decreasing apoptosis in human osteoarthritic cartilage. Experimental Cell Research, 352: 146-156. DOI: https://doi.org/10.1016/j.yexcr.2017.02.012

Pasquini C, Spurgeon T, and Pasquini S (2007). Anatomy of domestic animals stemic and regional approach. 11th ed. Pilot Point: Sudz; Available at: https://cmc.marmot.org/Record/.b16246482

Reurink G, Goudswaard GJ, Moen MH, Weir A, Verhaar JAN, and Bierma-Zeinstra SMA (2014). Platelet-rich plasma injections in acute muscle injury. New England Journal of Medicine, 370: 2546-2547. DOI: https://doi.org/10.1056/NEJMc1402340

Rubio-Azpeitia E, and Andia I (2014). Partnership between platelet-rich plasma and mesenchymal stem cells: in vitro experience. Muscles, Ligaments and Tendons Journal, 4(1): 52-62. Available at: https://www.ncbi.nlm.nih.gov/pmc/articles/PMC4049651/

Schnabel LV, Mohammed HO, Miller BJ, McDermott WG, Jacobson MS, and Santangelo KS (2007). Platelet rich plasma (PRP) enhances anabolic gene expression patterns in flexor digitorum superficialis tendons. Journal of Orthopedic Research, 25(2): 230-240. DOI: https://doi.org/10.1002/jor.20278

Smith JJ, Ross MW, and Smith RK (2006). Anabolic effects of acellular bone marrow, platelet rich plasma, and serum on equine suspensory ligament fibroblasts in vitro. Veterinary Comparative Orthopedic Traumatology, 19(1): 43-47. DOI: https://doi.org/10.1055/s-0038-1632972

Smyth NA, Murawski CD, Fortier LA, Cole BJ, and Kennedy JG (2013). Platelet-rich plasma in the pathologic processes of cartilage: review of basic science evidence. Arthroscopy, 29(8): 1399-1409. DOI: https://doi.org/10.1016/j.arthro.2013.03.004

Textor JA, and Tablin F (2012). Activation of equine platelet-rich plasma: comparison of methods and characterization of equine autologous thrombin. Veterinary Surgery, 41: 784-794. DOI: https://doi.org/10.1111/j.1532-950X.2012.01016.x

Vaughn-Scott T, and Taylor JH (1997). The pathophysiology and medical management of canine osteoarthritis. J S Africa Assoc, 68: 21-25. DOI: https://doi.org/10.4102/jsava.v68i1.861

Wijekoon HMS, Kim S, Bwalya EC, Fang J, Aoshima K, Hosoya K, and Okumura M (2019). Anti-arthritis effect of pentosan polysulfate in collagen induced arthritis rats. Research in Veterinary Science, 122: 179-185. DOI: https://doi.org/10.1016/j.rvsc.2018.11.028

Xie X, Wang Y, Zhao C, Guo S, Liu S, and Jia W (2012). Comparative evaluation of MSCs from bone marrow and adipose tissue seeded in PRPderived scaffold for cartilage regeneration. Biomaterials, 33: 7008-7018. DOI: https://doi.org/10.1016/j.biomaterials.2012.06.058

Zhang J, Middleton KK, Fu FH, Im HJ, and Wang JH (2013). HGF mediates the anti-inflammatory effects of PRP on injured tendons. PlosOne, 8: e67303. DOI: https://doi.org/10.1371/journal.pone.0067303

Zhu Y, Yuan M, Meng HY, Wang AY, Guo QY, and Wang Y (2013). Basic science and clinical application of platelet-rich plasma for cartilage defects and osteoarthritis: a review. Osteoarthritis Cartilage, 21(11): 1627-1637. DOI: https://doi.org/10.1016/j.joca.2013.07.017

Zimmermann G, and Moghaddam A (2011). Allograft bone matrix versus synthetic bone graft substitutes. Injury, 42: 16-21. DOI: https://doi.org/10.1016/j.injury.2011.06.199 